\title{
ASSESSMENT OF THE STATUS OF LATES STAPPERSII (CENTROPOMIDAE) STOCK IN LIFT-NET FISHERY IN LAKE TANGANYIKA, KIGOMA, TANZANIA
}

\author{
${ }^{1}$ IA Kimirei and ${ }^{2}$ YD Mgaya \\ ${ }^{I}$ Tanzania Fisheries Research Institute, Box 90, Kigoma Tanzania.kiakimirei@yahoo.com \\ ${ }^{2}$ Faculty of Aquatic Sciences and Technology, University of Dar es Salaam, \\ P.O. Box 60091, Dar es Salaam, Tanzania.ymgaya@udsm.ac.tz (Corresponding author)
}

\begin{abstract}
An assessment of the status of Lates stappersii (Boulenger, 1914) stock in the lift-net fishery in Lake Tanganyika, Kigoma area, was carried out from January to December 2003. Results indicated that breeding is seasonal with peaks in February, July-August and December, and so was catch composition, with peaks in March, May and July-August that followed the abundance of its prey, Stolothrissa tanganicae. Catch per unit effort was similar between wet and dry seasons and peaked synchronously at all study sites probably as an indication of its abundance during those months; but also it could mean that the fishes were caught from the same general area. The unselective nature of the lift-net, a common fishing gear in the lake, could be exerting pressure on the pelagic resource, that leads to local over-fishing if not controlled. There is need to institute minimum fish size and mesh size limits and licensing, on a lake-wide basis, as fisheries management measures to safeguard against overexploitation of this highly variable and mobile yet important pelagic fish resource.
\end{abstract}

\section{INTRODUCTION}

There are four endemic Lates species to Lake Tanganyika, namely L a tes mariae (Steindachner), Lates microlepis (Boulenger), Lates angustifrons (Boulenger), and Lates stappersii (Boulenger) (Coulter 1991). The first three species were once important but their catch has declined after years of exploitation (Coulter 1988, Pearce 1988, Roest 1992). They are to-date, incidental in the pelagic catch (Chitamwebwa and Kimirei 2005). Recent studies have concentrated on $L$. stappersii because of its increased importance in the pelagic fishery (Coulter 1988, 1991, Moreau and Nyakageni 1992) and its economic and nutritional importance to the riparian states. However, since the 1970s, L. stappersii catches have declined in the northern sector of the lake (Burundi) where it was once an important component of the pelagic fishery (Coulter 1970, 1976, Shirakihara et al. 1992, Coenen 1995, Mannini 1998). L. stappersii contributes between $30 \%$ and $50 \%$ of the pelagic catch in the Burundi sector (Roest 1988). L. stappersii is now important in the southern sector of the lake (Zambia) (Coenen et al. 1998, Phiri and Shirakihara 1999), where since the 1980s it has replaced Stolothrissa tanganicae in the industrial purse seine fishery. It now contributes up to $95 \%$ of the catch (Mannini 1998); however, a scenario of local over-fishing was reported by Coenen et al. (1998).

Local over-fishing is thought to have resulted in the observed decline of catch in the D.R. Congo (Mulimbwa, pers. comm.). L. stappersii was the main component of the pelagic fishery in the Kigoma area, making up over $60 \%$ of the pelagic catch, until the mid 1990s when an overall $S$. tanganicae dominance became apparent (Chitamwebwa and Kimirei 2005). To-date, $S$. tanganicae dominates the pelagic fishery landings contributing over $70 \%$ of the catch (Mannini 1998). The decline in $L$. stappersii catches is thought to be linked to both climatic changes and over-exploitation (Plisnier 1997, Mannini 1998, Coenen et al. 1998, Chitamwebwa and Kimirei 2005, 
Kimirei and Mgaya 2007). L. stappersii contributes substantially to the economy and dietary protein for the ever growing population around Kigoma. Fluctuations and decline in the L. stappersii catch not only affect the nutrition but also the economy of the population living in the area and the lake at large. The causes for the variability and decline are poorly understood.

The objectives of the present study were to examine the seasonal abundance of $L$. stappersii in the lift-net fishery catches and to identify possible causes of the fluctuations in its abundance in the Kigoma area (Tanzania).

\section{MATERIALS AND METHODS}

Fishing on Lake Tanganyika is done at night by light attraction using pressure lamps. Bi-weekly catch $(\mathrm{kg})$ and effort (number of lamps and hauls), mesh size, species composition, length - weight measurements, and sexual maturity stages/breeding season data of L. stappersii were collected from three landing stations, Kibirizi, Kigodeco and Katonga, around Kigoma area of Lake Tanganyika (Fig. 1). Five lift-net fishing units were sampled every sampling visit. The number of lamps (13.19 \pm SD 2.66) was used as a measure of fishing effort to calculate catch per unit effort (CPUE) because the number of hauls $(2.04 \pm$ SD 0.51) seems to be constant and so its use as a measure of fishing effort would underestimate the magnitude of exploitation of this resource by the lift-net fishery in the area. Moreover, historical catch data for the period 1993 to 1996 were obtained from the Fisheries Division of the Ministry of Natural Resources and Tourism and used to shed light on the historical trends in the fishery.

Total catch in kilogrammes was obtained by multiplying the number of standard boxes filled with either $L$. stappersii or $S$. tanganicae by $60 \mathrm{~kg}$. A sub-sample of about $5 \mathrm{~kg}$ for L. stappersii and because the liftnets used for the multi-species fisheries are not selective in nature, $0.5 \mathrm{~kg}$ of the mixed catches of $S$. tanganicae and L. stappersii juveniles were collected for further laboratory analysis. In the laboratory, fishes in the mixed catch sample were sorted according to species and individual total length (from the snout to the tip of the largest caudal fin ray) measured to the nearest millimeter using a measuring board. Body weight was measured to the nearest gram using a top pan balance and a spring balance for juveniles and adults, respectively. Length and weight data were used to establish a length-weight relationship (equation 1) from which a monthly average Fulton's condition factor (K) (equation 2) was obtained:

$W=a L^{b}$

$K=\left(W / \overline{L^{3}}\right) * 10^{x}$

where $\mathrm{W}$ is weight of the fish in grammes, $\mathrm{L}$ is the total length $(\mathrm{mm}), \mathrm{K}$ is the condition factor, $a$ and $b$ are constants, and $10^{x}$ is a scaling factor; $x=4$ was used.

Maturity stages were recorded according to the six point scale adopted from King (1995). All individuals whose gonads were identified as immature were assigned maturity stage I, while stages II, III, IV, V and VI represented developing, mature, riperunning, spawning and spent individuals respectively. However, for analysis purpose, stage VI was categorized as mature and grouped together with stage V. Stage IV individuals were not recorded at all over the study period. Size at the onset of maturity was taken as the minimum length at which $50 \%$ of the fishes, males and females separately, were mature (Ellis 1971, King 1995). All stages III to VI individuals were considered as mature while stages I and II were regarded immature. The values (percentage) corresponding to lengths of individual fishes were put in an ogive model to determine size at first maturity. 


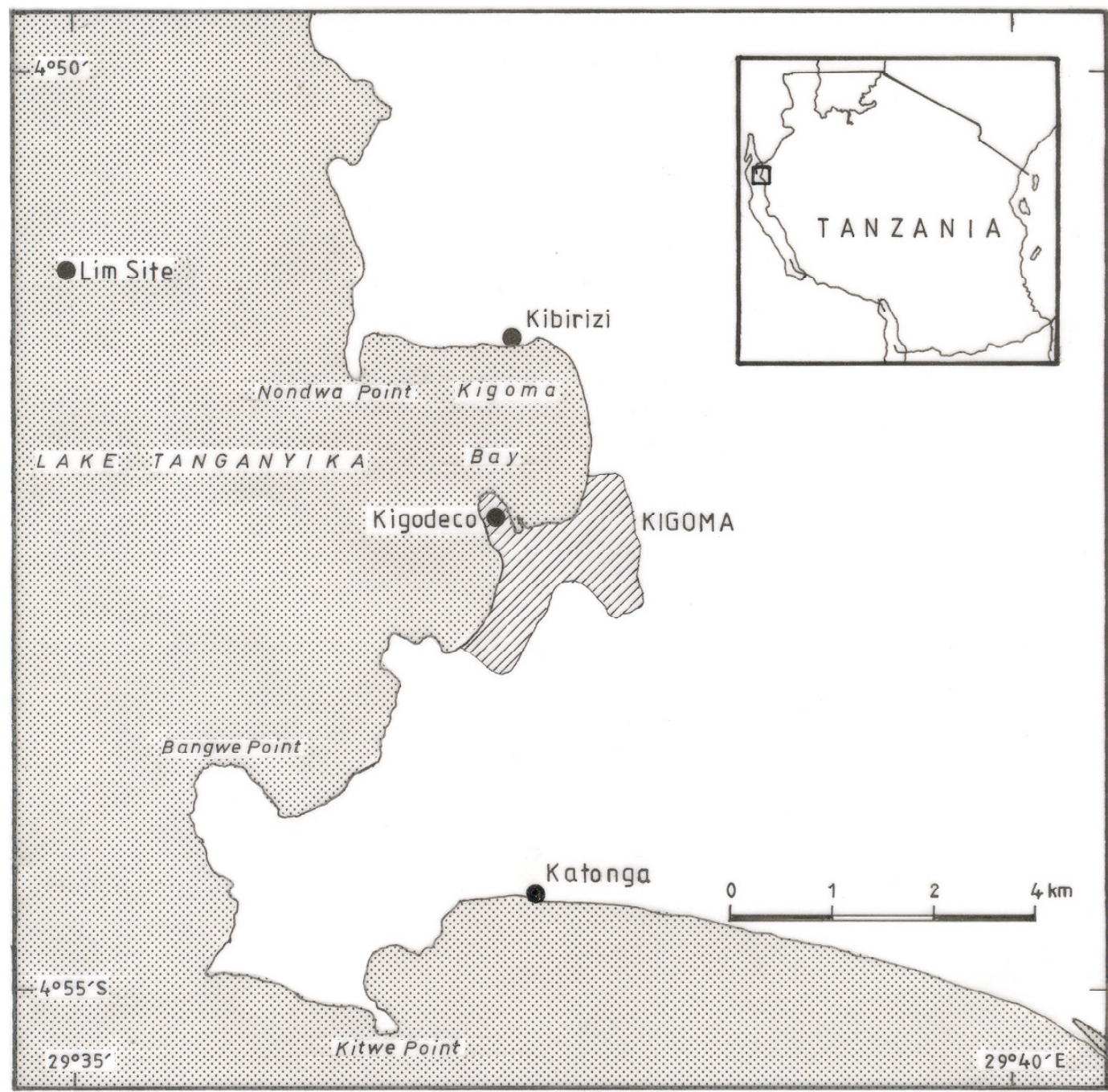

Figure 1: Map of Lake Tanganyika showing the sampling sites namely Kibirizi, Katonga and Kigodeco.

L. stappersii individuals were arbitrarily categorized as juveniles ( $<160 \mathrm{~mm}$ TL) or adults $(>160 \mathrm{~mm}$ TL) for analysis purposes. The periods September - April and May August were defined as wet and dry seasons, respectively.

\section{Data analysis}

Descriptive statistics were used to compute percentage compositions of L. stappersii in the catch. Seasonal trends in catch rates and breeding pattern were analyzed using a nonparametric Mann-Whitney $U$ test, because the data were not normally distributed. Regression analysis and a special t-test were used to test for isometric growth pattern of L. stappersii. Monthly length frequency data were pooled to produce a frequency distribution histogram. 


\section{RESULTS}

There were more L. stappersii, over the study period, in the area during February, May and July-August combined than during the other months $(\mathrm{t}=6.349, \mathrm{DF}=7, \mathrm{p}<$ 0.001 ) (Fig. 2A). Catch rates were similar for all the landing sites with peaks in February, May and July - August (Fig. 2B).
This may indicate that all the fishes were caught from the same general area and that these are times when L. stappersii is most abundant in the pelagic catch in Kigoma area. There was no clear seasonality in CPUE in the area between wet and dry seasons $\left(\mathrm{U}^{\prime}=22.0, \mathrm{p}=0.35\right)$.

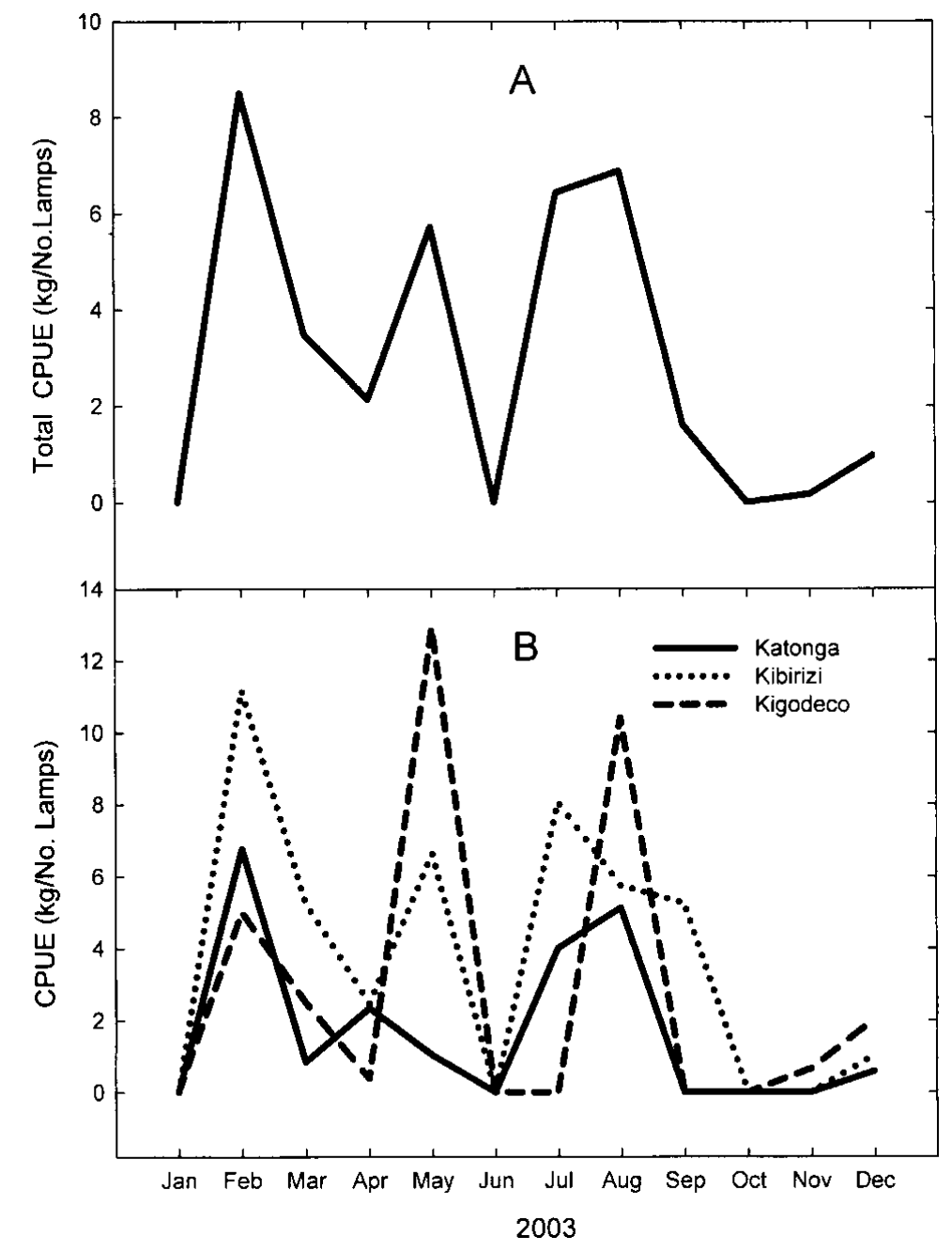

Figure 2: $\quad$ A: Seasonal variations in total CPUE for Lates stappersii in Kigoma area of Lake Tanganyika. B: Seasonal variations by site of Lates stappersii abundance in the Kigoma area of Lake Tanganyika. 
Compared with other components of the pelagic fishery (Stolothrissa tanganicae and Limnothrissa miodon), L. stappersii was the second most important species in the catch with the minimum percentage recorded during September - December, at the onset of rains. It contributed only $14.19 \%$ of the total catch over the study period with the clupeid $S$. tanganicae dominating the catch $(84.51 \%)$ and the rest $(1.3 \%)$ being contributed by another relatively less important clupeid, L. miodon, in the Kigoma area. Generally, L. stappersii made a substantial but statistically insignificant $\left(U^{\prime}=1572.5, p=0.239\right)$ contribution to the catch during the rainy season (January May). L. stappersii contribution varied from 0 to $33.85 \%$ (Fig. 3A). Historical catch data analyzed for the period 1993 to 1996 indicated that L. stappersii was very important, almost equaled the contribution by clupeids in 1993 and 1994, however, from 1995 its contribution declined leaving $S$. tanganicae to dominate the catch. $L$. stappersii contributed less than 25 and $40 \%$ in 1995 and 1996 respectively (Fig. 3B).

Length-frequency distribution from pooled monthly length-frequency data for $L$. stappersii is presented in Fig. 4. Several groups/cohorts are discernible; however, there seems to be little/negligible amount of individuals with size classes between 200 and $260 \mathrm{~mm}$. Juveniles ( $<160 \mathrm{~mm} \mathrm{TL})$ of L. stappersii were always present in the catch however, they were more abundant during the rainy season, September- October and February - May.
Immature individuals (stage I) dominated the catch of $L$. stappersii over the sampling period. Although the seasonal abundance of immature individuals was statistically not significant $\left(U^{\prime}=20, p=0.570\right)$, these individuals were dominant during the wet season (September/October - April/May) (Fig. 5). Stage V individuals were always present except in January, September and November where over $80 \%$ of all $L$. stappersii sampled were juveniles/immature. All individuals caught in December were mature giving a sense of breeding aggregations for this species. There was a seasonal variation in Fulton's condition factor $(\mathrm{K})$ of $L$. stappersii. It increased during the main spawning periods (February, July-August and December) while a drop was observed during January, MarchMay, and September-November when the catch constituted more of the immature, stage I, individuals of $L$. stappersii. The Fulton's condition factor $(\mathrm{K})$ remained high for stage $\mathrm{V}$ individuals indicating that spawning individuals were in good condition (Fig. 6)

The length and weight data were tested for isometry using regression analysis and a special t-test was used to test if the slope $b$ $=3$. The results $(\mathrm{t}=1.960, \mathrm{p}<0.0001)$ indicated that $L$. stappersii exhibited an isometric growth pattern with a lengthweight relationship defined by the equation: $\mathrm{W}(\mathrm{g})=3 * 10^{-06} \mathrm{TL}^{3.1783}\left(\mathrm{n}=1428, \mathrm{r}^{2}=\right.$ $0.9901)$. The size at first maturity for females L. stappersii was $218 \mathrm{~mm}$ TL and that of males was $202 \mathrm{~mm}$ TL. 

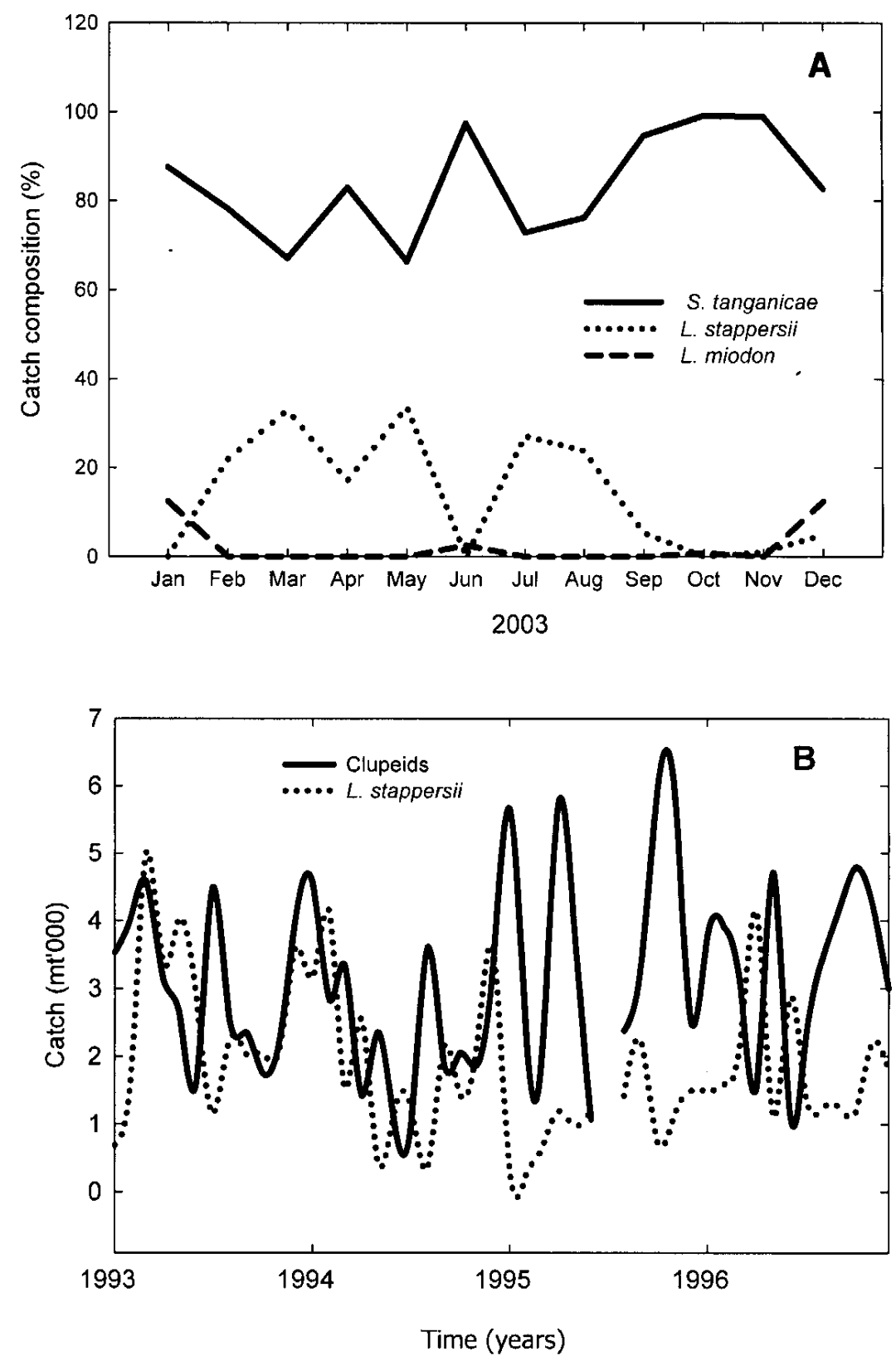

Figure 3: A: Catch compositions of the three most important pelagic fish species in the Kigoma area, Lake Tanganyika, indicating the relative importance of Lates stappersii in the pelagic fish catch. B: Historical catch composition of the pelagic fishery in the Kigoma area of Lake Tanganyika indicating the declining relative importance of Lates stappersii in the pelagic catches after December 1994. 


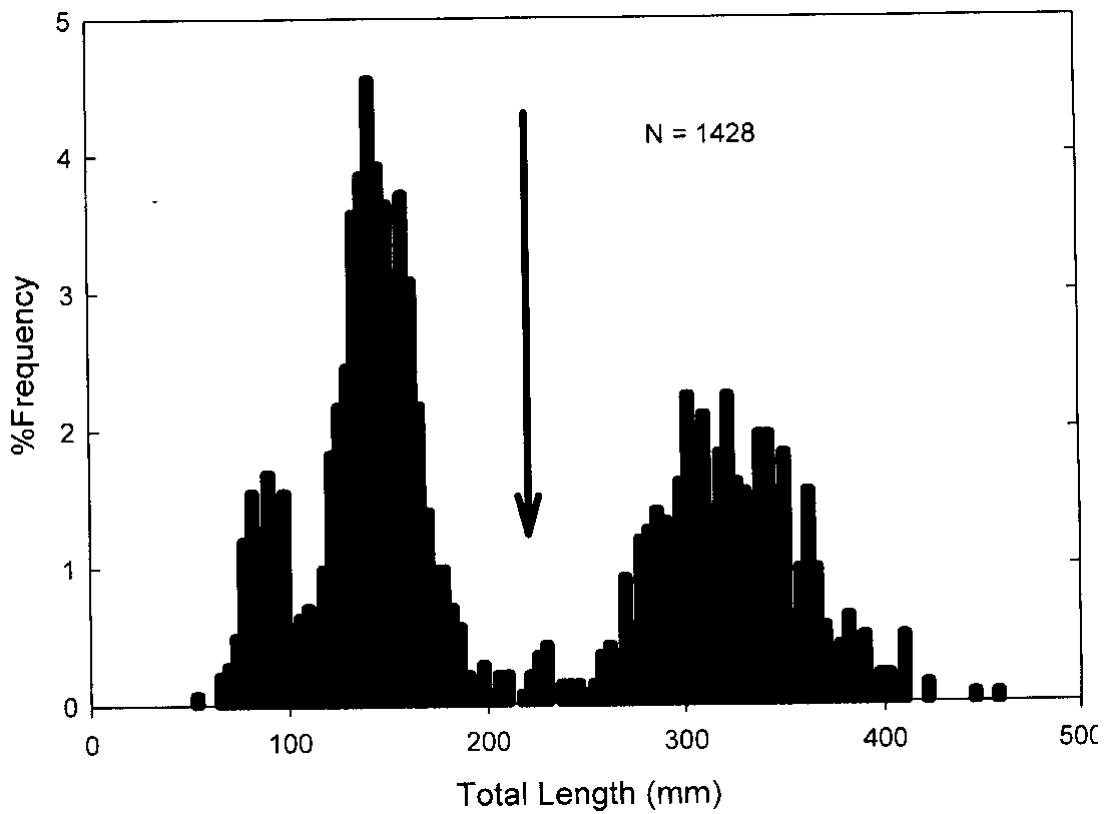

Figure 4: Length-frequency distribution for the pooled length frequency data of Lates stappersii over the sampling period (Jan - Dec 2003). The arrow indicates the absence of the new spawning individuals (200 -250 $\mathrm{mm})$.

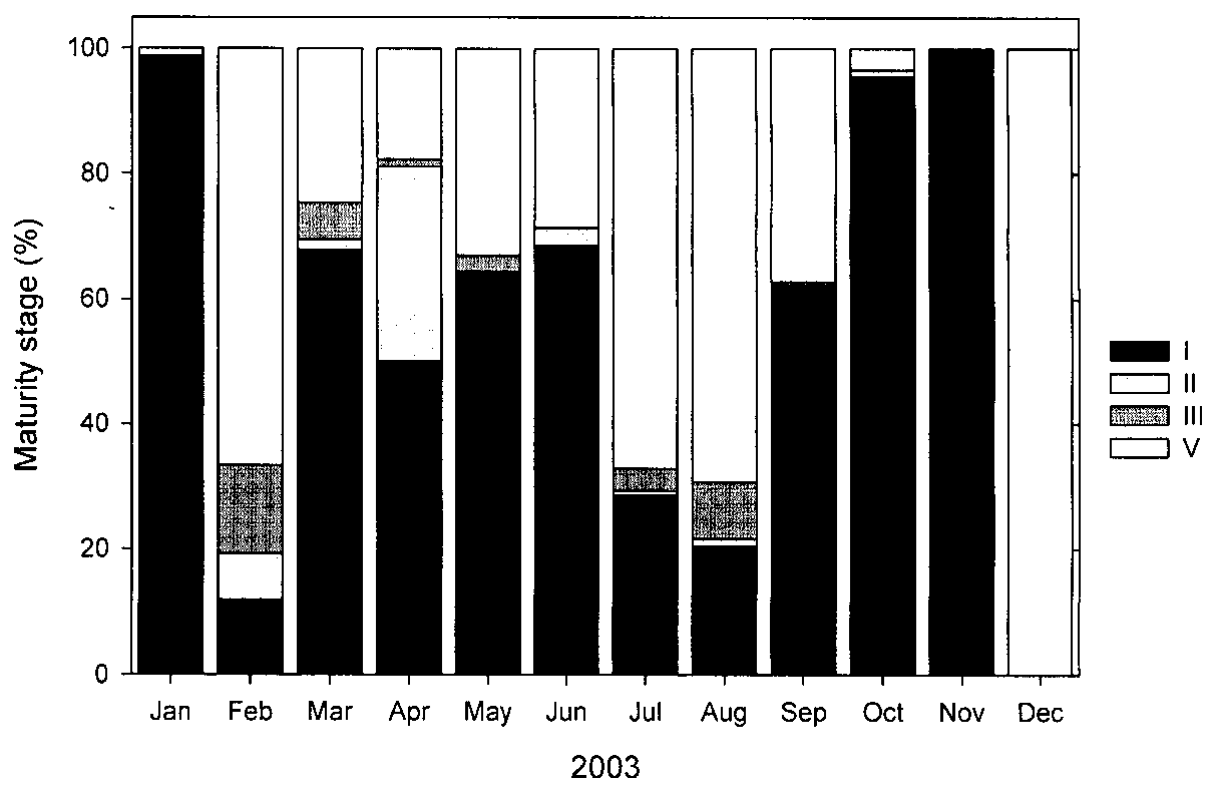

Figure 5: $\quad$ Seasonal variation in maturity stages of Lates stappersii in the Kigoma area of Lake Tanganyika. I - immature, II - developing, III - mature and V - spawning; stage IV was not encountered while stage VI was grouped with stage V for analysis purpose. 


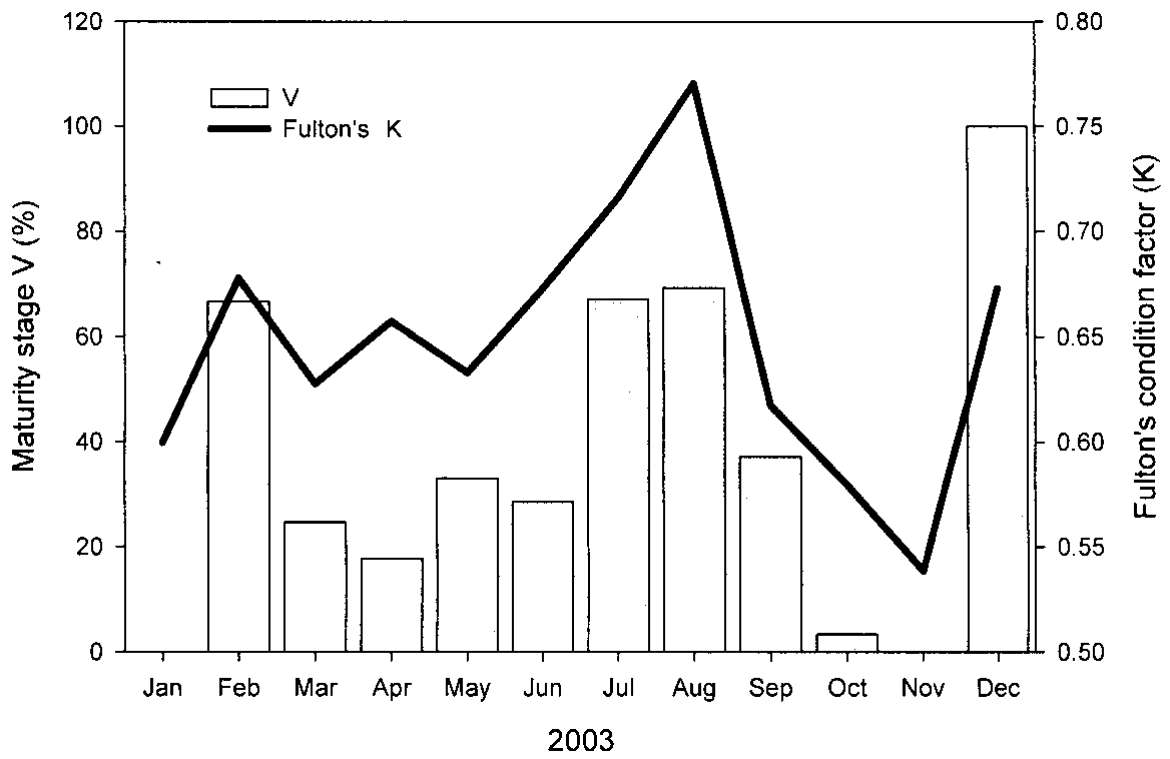

Figure 6: Seasonal variations between the condition factor $(\mathrm{K})$ and stage $\mathrm{V}$ individuals of Lates stappersii in the Kigoma area of Lake Tanganyika.

\section{DISCUSSION}

Lates stappersii is known to be highly mobile capable of moving across the whole length of the lake (FAO 1978, Roest 1992). However, there is still no concrete evidence regarding large scale movements of this species (Mannini 1998), despite the fact that Phiri and Shirakihara (1999) have reported considerable seasonal movements of this species out of the Zambian waters. From the analysis of catch rates presented herein, $L$. stappersii seems to be evenly distributed in the Kigoma area; however, a lake-wide uneven distribution of this species has recently been reported by Mannini (1998). Mannini (1998) reported that L. stappersii occurs in all lake areas with the central lake area from Kigoma to East Marungu (D.R. Congo), characterized by steep shores, reduced shelf and where the deepest areas are located, being the optimal habitats for this species. The present study has revealed that relative abundance and composition of $L$. stappersii declined, followed by an increase in $S$. tanganicae (Figures $3 \& 4$ ), an indication of a strong predator-prey relationship (Chapman and van Well 1978, Roest 1988).

The study by Mannini (1998), using lakewide acoustic and pelagic trawl surveys between June 1995 and February 1998, indicated the dominance of $L$. stappersii in the south and $S$. tanganicae in the northern half. L. stappersii seems to have been important in the catch during breeding times when larger, mature, individuals were dominant. The decline in L. stappersii, therefore, may indicate biomass decay of these large breeding individuals. However, L. stappersii is the principal predator of $S$. tanganicae; and their catches are strongly negatively correlated (Coulter 1991, Mannini 1998). Its movements therefore, seem to be determined in part by the movements of its prey, S. tanganicae. The high relative abundance observed in February and July-August coincided with the annual maximum abundance of its prey also reported by Mannini (1998) and Kimirei and Mgaya (2007). Because lift-nets are legally constructed with net webbing of $10 \mathrm{~mm}$, large catches of only juvenile $L$. 
stappersii are sometimes realized. The juveniles are also caught with adults of $S$. tanganicae. The mixed occurrence of juvenile $L$. stappersii and adult $S$. tanganicae could be explained by competition for food between them, rather than light attraction, as the two species are zooplanktivorous (Coulter 1991).

Juveniles and adults of L. stappersii cooccur within a geographical area although their inshore-offshore distribution differs (Mannini 1998). Because of the unselective nature of the nets used in catching the pelagic fishes, sometimes codends of $<6$ $\mathrm{mm}$ stretched mesh size are used (Pers. Obs) resulting in heavy exploitation of juveniles of L. stappersii. Large amounts of juvenile L. stappersii are caught together with adults of $S$. tanganicae (Pers. Obs.). The Kigoma area may serve both as a spawning and nursery ground due to the presence of both juveniles and sexually mature individuals. With the intensity of the lift-net fishing and its efficiency experienced today, it is likely that both recruitment and growth overfishing of L. stappersii might have occurred resulting in the current overall dominance of the clupeid, $S$. tanganicae, in the catches. This is reflected by the mode of sexually mature and spawning individuals at 230-250 $\mathrm{mm}$ (Ellis 1978) is negligibly small from a frequency distribution of the pooled length frequency data.

Migration alone, of L. stappersii stock from the Kigoma area to other areas, especially the southern part of the lake, cannot explain its observed decline in the pelagic catch in the area and the northern end of the lake. Migration together with the predator-prey relationship between this species and the clupeids could account for seasonal abundance. Although no concrete evidence exists for local over-fishing (Shirakihara et al. 1992) and the suggestion by Mannini (1998) that the fishery can still be sustained in the southern part of the lake, the fishing pressure in the area is mounting. Chitamwebwa and Kimirei (2005) reported a fishing intensity to the tune of more than 400 lift-net units in the study area alone, which could also be an underestimate. If fishing effort is not monitored/controlled the end result will be a total collapse of the $L$. stappersii fishery in the Kigoma area and probably the whole lake, as this is probably an important spawning and nursery ground. A little expansion of the pelagic fishery in this area and the East Marungu, another spawning and nursery ground (Mannini 1998), or any move of the industrial fishing units in the south to follow the $L$. stappersii stock in these lightly fished areas, could result in a serious decline of the stocks. To-date, the pelagic catches are dominated by $S$. tanganicae, which contributes over $80 \%$. This is in line with Coulter's (1981) predictions that with increasing fishing pressure L. stappersii will become scarce. Unlike $S$. tanganicae which is short lived (approximately 1 year), $L$. stappersii has a life span of about 5 to 7 years (Mulimbwa and Mannini 1993, Mannini 1998) and so would be depleted faster than S. tanganicae.

In conclusion, looking at the fishery from a 'classical' fisheries management perspective, the fishing effort may be high and could be the major factor affecting the realization of good catches in the area (Chitamwebwa and Kimirei 2005). However, from an ecosystem perspective, climate change cannot be ignored as one of the contributing factors to the observed declining stocks as suggested by O'Reilly et al. (2003) and Verburg et al. (2003). Several management measures can be applied on the fishery, after appropriate research on a suitable mesh size to be used in the fishery has been conducted, in order to minimize the exploitation pressure on $L$. stappersii and the pelagic fishery at large. These may include but not limited to closures, both spatial and temporal, minimum mesh sizes and size limits where minimum legal lengths are set. The last two have been successful in Lake Victoria. In addition, expansion of the fishery should be limited by allowing a limited number of 
Kimirei and Mgaya - Assessment of the status of Lates stappersii ...

fishers and fishing vessels through licensing. However, licensing should be used as a means of controlling the fishery rather than for revenue collection sake. It is also important to harmonize enforcement of management measures in all the riparian countries since the depletion of stocks in one part will consequently affect other areas.

\section{ACKNOWLEDGEMENTS}

This work is a result of many concerted efforts of a number of individuals. We thank everybody who in one way or another invested his or her effort. We thank the Belgian Science Policy Office (SPO), in particular, for funding the research in the frame of the CLIMLAKE Project (Climate variability as recorded in Lake Tanganyika). The manuscript benefited from comments and suggestions of anonymous reviewers to whom we are grateful.

\section{REFERENCES}

Chapman DW and van Well P 1978 Observation on the biology of Luciolates stappersii in Lake Tanganyika (Tanzania). Trans. Amer. Fish. Soc. 107: 567-73.

Chitamwebwa DBR and Kimirei IA 2005 Present catch trends at Kigoma, Tanzania. Mitt. Int. Ver. Theor. Ang. Limn. 29(1): 373-376.

Coenen EJ 1995 LTR's fisheries statistics subcomponent: March 1995 update of results for Lake Tanganyika. FAO/FINNIDA Research for the Management of Fisheries of Lake Tanganyika. GCP/RAF/271/FINTD/32 (EN.): 45 pp.

Coenen EJ, Paffen P and Nikomeze E 1998 Catch per unit effort (CPUE) study for different areas and fishing gears of Lake Tanganyika. FAO/FINNIDA Research for the Management of the Fisheries on Lake Tanganyika GCP/RAF/271/FIN-TD/80 (EN.): 92 pp.

Coulter GW 1970 Population changes within a group of fish species in Lake
Tanganyika following exploitation. $J$. Fish. Biol. 2: 329-353.

Coulter GW 1976 The biology of Lates species (Nile perch) in Lake Tanganyika, and Luciolates stappersii (Blgr.). J. Fish. Biol. 9: 235-259.

Coulter GW 1981 Biomass, production and potential yield of the Lake Tanganyika fish community. Trans. Amer. Fish. Soc. 110: 325-355.

Coulter GW 1988 Production dynamics in Lake Tanganyika. In: Lewis D (ed) Predator - prey relationships, population dynamics and fisheries productivities of large African lakes. CIFA Occ. Pap. (15): 154 pp.

Coulter GW (ed) 1991 Lake Tanganyika and its life. Natural History Publications, Oxford University Press, London. 354 pp.

Eccles DH 1992 Field Guide to the Freshwater Fishes of Tanzania. FAO, Rome, 145 pp.

FAO 1978 Fishery biology and stock assessment. UN/FAO Technical Report, DP/URT/71/012/1: 1-37.

Kimirei IA and Mgaya YD 2007 Influence of environmental factors on seasonal changes in clupeid catches in the Kigoma area of Lake Tanganyika. Afr. J. Aq. Sci. 32(3): 00-00. (In press)

King M 1995 Fisheries biology, assessment and management. Fishing News Books, Oxford. 342 pp.

Mannini P 1998 Geographical distribution patterns of pelagic fishes and macrozooplankton $\mathrm{n}$ Lake Tanganyika. FAO/FNNDA. Research for the Management of the Fisheries of Lake Tanganyika. GCP/RAF/271/FINTD/83 (EN): 125 pp.

Mulimbwa N and Mannini P 1993 Demographic characteristics of Stolothrissa tanganicae, Limnothrissa miodon and Lates stappersii in the northwestern (Zairean) waters of Lake Tanganyika. In: Marshall $\mathrm{BE}$ and $\mathrm{R}$ Mubamba (eds) Papers presented at the symposium on biology, stock assessment and exploitation of small 
pelagic fish species in the African Great Lakes region. Bujumbura, Burundi, from 25-28 $8^{\text {th }}$, November 1992. CIFA Occ. Pap. (19): 270 p.

O'Reilly CM, Alin SR, Plisnier PD, Cohen AS and McKee BA 2003 Climate change decreases aquatic productivity in Lake Tanganyika, Africa. Nature 424: 766-768.

Pearce JM 1988 Some effects of Lates spp. on pelagic and demersal fish in Zambian waters of Lake Tanganyika. In: Lewis D (ed) Predator - prey relationships, population dynamics and fisheries productivities of large African lakes. CIFA Occ. Pap. (15): $154 \mathrm{pp}$.

Plisnier PD 1997 Climate, limnology and fisheries changes of Lake Tanganyika. FAO/FINNIDA Research for the Management of Fisheries on Lake
Tanganyika GCP/RAF/271/FIN-TD/72 (En): 50 pp.

Roest CF 1988 Predator-prey relations in northern Lake Tanganyika and fluctuations in the pelagic fish stocks. In: Lewis D (ed) Predator - prey relationships, population dynamics and fisheries productivities of large African lakes. CIFA Occ. Pap. (15): $154 \mathrm{pp}$.

Roest CF 1992 The pelagic fisheries resources of Lake Tanganyika. Mitt. Int. Ver. Theor. Ang. Limn. 23: 11-15.

Shirakihara K, Use K, Kamikawa S Mambona Wa B 1992 Population changes of sardines in northern Lake Tanganyika. Afr. Stu. Monog. 13(1): 57-67.

Verburg P, Hecky RE and Kling H 2003 Ecological consequences of a century of warming in Lake Tanganyika. Science 301: 505-507. 